\title{
Wits Appraisal Among Qatari Females: A Comparative Study
}

\author{
Hayder Abdalla Hashim, Najah AL-Sayed, Feras Abed AL Jawad, Ayah AL-Qaisi
}

\begin{abstract}
Introduction: The goal of cephalometric analysis is to determine the skeletal and dental relationships that exist in an individual patient. The objectives of the present study were to establish the Wits appraisal for Qatari females and to compare the results with previous reported results in different racial groups.

Materials and Methods: The sample consisted of 34 lateral cephalometric radiographs of Qatari female patients with age range from 18 to 25 years old presented with well-balanced face and acceptable profile.

Results: The mean value of the Wits appraisal for Qatari females in the present study was $\mathbf{- 0 . 6 2} \pm \mathbf{3 . 8}$. The Wits appraisal mean value of the present study revealed that no statistically significant difference between the Qatari females and the original data of Jacobson. On the other hand, significant differences were found when compared to other populations from several reports.

Conclusion: The Wits appraisal among Qatari females was $\mathbf{- 0 . 6 2}$ with standard deviation of 3.8. Care should be taken in growing and developing children where variation in dental height exists and may confuse the Wits value. The Wits appraisal could be used as a moderator to ANB angle in boarder line cases. It is recommended to incorporate angular measurements using 3D imaging software which increases diagnostic accuracy for the least amount of existed discrepancy.
\end{abstract}

Index Terms - Cephalometric; Orthodontic treatment; Wits appraisal.

\section{INTRODUCTION}

The goal of cephalometric analysis is to determine the skeletal and dental relationships that exist in an individual patient [1], [2]. This is by comparing the individual's measurements with a normal reference group, so that differences between the patient's actual dentofacial relationships and those expected for his or her racial or ethnic group are revealed [3]-[10]. The most common angle used was the ANB angle suggested by Rediel [11] and used by Steiner [12]. It indicates the antero-posterior relationship between the maxilla represented by (SNA) angle and the mandible represented by (SNB) angle [13], [14]. However, it is reported that ANB angle is not without limitations with respect to its accuracy due to several factors. Among these factors include age, the spatial position of Nasion point, the upward or downward rotation of the jaw or the anterior cranial base change in relation to the occlusal plane, and the degree of facial prognathism [15]-[18]. To eliminate the

Published on July 11, 2020.

H. A. Hashim, Hamad dental Centre, Qatar.

(e-mail: e-mail: hahashim78@yahoo.com). effect of these factors, a proposed diagnostic tool was introduced by Jenkins [19] and later was modified by Jacobson as "Wits" appraisal [9] Jacobson introduced the Wits appraisal as a reliable indicator of the sagittal relationship between the maxilla and the mandible. He drew a perpendicular line from Point A and Point B to the occlusal plane [9]. The horizontal linear measurement between the perpendicular lines indicate the skeletal relationship between the maxilla and the mandible. His sample consisted of 21 adult subjects with excellent occlusion and noticed that point BO was approximately $1 \mathrm{~mm}$ ahead of point AO. With a range of -2 to $4 \mathrm{~mm}$ and mean reading of $1.17 \pm 1.9 \mathrm{~mm}$.

Since then, several studies were conducted in different races to establish the Wits value. Robertson and Pearson found in sample from South wales that the Wits appraisal was $0.1 \pm 1.9$ in males and $0.3 \pm 1.7 \mathrm{~mm}$ in females.[20] On the other hand, the Wits appraisal in a South Chinese sample was $4.88 \pm 3.61$ in males and $-4.47 \pm 4.19 \mathrm{~mm}$ in female [21]. Whereas in Nigerians it was $-4.15 \pm 3.65 \mathrm{~mm}$ for males and in females was $-3.06 \pm 2.96$ [22]

In addition to the aforementioned studies, few reports from the Arab populations were published such as the study of AlBarakati who established the Wits value in a group of Saudi dental students and concluded that there was no significant difference between her sample and the original sample of Jacobson [23]. However, she found significant differences when she compared her sample to other samples such as, the Chinese and British Caucasians. On the contrary, Zawawi in another group of Saudi samples found that there was significant difference between males and females $(-0.73 \pm 2.48$ and $1.79 \pm 2.06$ respectively). He stated that Wits appraisal appears to be more gender-specific and less ethnicityspecific.

In the State of Qatar, there is no data on the Wits values. Therefore, the aims of this study are to establish the Wits values in a sample of Qatari female individuals and to compare the results with other populations from different racial and ethnic backgrounds reported in the literature.

\section{MATERIAL AND METHOD}

\section{A. Subjects}

The sample consisted of 34 lateral cephalometric radiographs of Qatari female patients with age range of 18 to 25 years old (Mean 20.69 \pm 4.9 years). There were no enough cephalometric radiographs for male patients to conduct an appropriate analysis and compare to female patients Therefore, measurements were made on female patients. They were selected according to the following criteria: well-

N. ALSayed, Hamad dental Centre, Qatar.

F.A. AL-Jawad, Hamad Dental Center, Qatar.

A. AL-Qaisi, Hamad Dental Centre, Qatar. 
balanced face and acceptable profile, skeletal class I and Class I occlusion with normal overjet and overbite, minor or no crowding or spacing, and no history of orthodontic treatment. Ethical approval and consent form were obtained.

\section{B. Method}

A good quality digital lateral skull radiograph was taken by Planmeca ProMax $(84 \mathrm{kV}-16 \mathrm{~mA}$. Total filtration $2.5 \mathrm{~mm}$ AI) manufactured in Finland. The radiograph was taken by well-trained technician at 5-feet from each patient looking straight to her own eyes on the mirror. Each radiograph was hand traced by one operator. The Wits appraisal was recorded by drawing straight perpendicular lines from Point A (Subnasale) and Point B (Supramentale) respectively to the functional occlusal plane at $90^{\circ}$ and measuring the horizontal distance from point $\mathrm{AO}$ to $\mathrm{BO}$. (Fig 1).

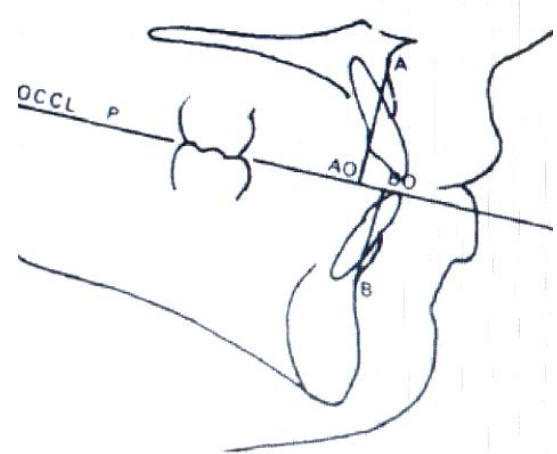

Fig 1 Wits appraisal.

\section{Statistical Analysis}

Microsoft Excel Program was used for the data analysis. Descriptive statistics, including the mean and SD were computed for each measurement. For analytical analysis, Student's t-test was used to assess whether there was significant difference between Wits appraisal in Qatari females and Jacobson data as well as with previously published data from other racial and ethnic groups. The level of significance was set at $\mathrm{p}<0.05$.

\section{RESULTS}

The error of the method was assessed by double measurements taken at least one-week interval on five randomly selected cephalograms. The t-test result indicated that no statistically significant differences between the two readings at $5 \%$ level. $(\mathrm{P}>0.05)$. According to Table $\mathrm{I}$, the mean value of the Wits appraisal for Qatari females in the present study was $-0.62 \pm 3.8$.

TABLE I: WITS APPRAISAL MEAN VALUES AND STANDARD DEVIATION FOR

\begin{tabular}{|c|c|c|c|}
\hline \multicolumn{1}{|c|}{ QATARI } \\
\hline Measurement & No. & Mean & SD \\
\hline Wits value for females & 34 & -0.62 & 3.8 \\
\hline
\end{tabular}

Table II revealed that there was no statistically significant difference between the Qatari females and Jacobson's data.

TABLE II: COMPARISON OF WITS MEAN VALUES BETWEEN THE PRESENT STUDY AND JACOBSON STUDY (1975)

\begin{tabular}{|c|c|c|c|c|c|}
\hline Ethnic group & No & Age & Mean & SD & P-Value \\
\hline Qatari & 34 & $18-25$ & -0.62 & 3.8 & \multirow{2}{0.5262}{} \\
Jacobson & 25 & Adult & -0.1 & 1.7 & NS \\
\hline
\end{tabular}

NS = Not Significant. P>0.05.

TABLE III: COMPARISON OF WITS MEAN VALUES BETWEEN QATARI FEMALES AND DIFFERENT RACES

\begin{tabular}{|l|c|c|c|c|c|}
\hline Ethnic group & No & Age & Mean & SD & P-Value \\
\hline Qatari & 34 & $18-25$ & -0.62 & 3.8 & \\
\hline $\begin{array}{l}\text { Saudi Central } \\
\text { Region }\end{array}$ & 30 & $22-23$ & 0.4 & 2.3 & $0.2062 \mathrm{NS}$ \\
\hline $\begin{array}{l}\text { Caucasian } \\
\text { Robertson and } \\
\text { Pearson (South } \\
\text { Wales) }\end{array}$ & 25 & 15 & -0.30 & 1.7 & $0.2696 \mathrm{NS}$ \\
\hline Kuwaiti & 162 & $13-14$ & -0.48 & 2.36 & $0.9778 \mathrm{NS}$ \\
\hline $\begin{array}{l}\text { Black North } \\
\text { American }\end{array}$ & 25 & $18-50$ & -0.3 & 3.05 & $0.7301 \mathrm{NS}$ \\
\hline $\begin{array}{l}\text { Nigerian } \\
\text { Black African }\end{array}$ & 66 & 66 & -3.06 & 2.96 & $0.0001^{* * *}$ \\
\hline Chinese & 46 & $10-15$ & -4.4 & 4.1 & $0.0001^{* * *}$ \\
\hline $\begin{array}{l}\text { Saudi western } \\
\text { Region }\end{array}$ & 41 & $13-14$ & 1.7 & 2.06 & $0.0090 * * *$ \\
\hline
\end{tabular}

*** $(\mathrm{P}<0.001)$ Extremely Significant. NS $(\mathrm{P}>0.05)$ Not Significant

No statistical significant differences were noted when comparing the present data with data from Jacobson, central region of Saudi Arabia, Kuwaiti and Black American. On the other hand, significant differences were noted when compared to data from Chinese, Nigerians and Western region of Saudi Arabia (Table III).

\section{DISCUSSION}

Cephalometric analysis is a key component for diagnosis, assessing growth changes and treatment planning for orthodontists by measuring not the relationship of teeth with the basal bone, but also the inter-relationship of jaw elements and cranial structures [25]. Therefore, Careful planning and analyzing the craniofacial structure is imperative in order to achieve favorable outcomes. Although ANB angle is the most common measurement to evaluate the sagittal relationship between jaws, it is not without limitations. As a result, other analyses were introduced to overcome the shortcomings of the ANB angle. Among these, is the Wits appraisal which was introduced by Jacobson in an attempt to give a better and adequate sagittal measurements for skeletal discrepancies of the maxilla and the madible by using the occlusal plane as a referrence instead of the cranial plane [9].

The mean value of the Wits appraisal in the present study revealed no statistical significant differences with the data of Jacobson. This finding was also consistent with other reports from other ethnic backgrounds such as, the South Walesh, Saudis, Kuwaitis [20], [23], [26], [27]. On the other hand, significant differences were revealed when compared to data from Chines, Nigerians and Western region of Saudi Arabia [21], [22]. Such differences could be attributed to the diversity of the ethnic background of the population investigated in these studies. Also could be related to the great systematic errors between the different studies, specifically when defining the occlusal plane. More over, Zawawi 
reported that, such variation in the definition between the observers; could lead to errors and those errors could be overcomed by well trained and calibrated reseachers to reduce the inter- and intra-examiner errors [24].

One draw back of Wits appraisal analyses is the vertical posterior inclination of the mandible in high angle cases. This high posterior vertical incilnation could affect the position of B point as well as the perpendicular line from B point to the occlusal plane by moving more posteriorly. One possible soultion to this; is cancelling this effect by establishing a formula of a figure as the same method proposed in case of Nasion point movement, which affect the inclination of the anterior cranial base line by substraction or addion of 7 degrees to all measured angles related to Nasion point or anterior cranial base.

Applying cone beam computed tomography (CBCT) could be of great help which give three dimensional view [28]-[29]. The outcome of such studies will supply the orthodontist with valuable information applicable to diagnosis and treatment planning. In support to this suggestion, Abou Kheir and Kau stated "Mathematical analysis is a valid method to measure mandibular asymmetry with respect to the third dimension which is usually absent in clinical photos and panoramic radiographs as well as cephalogram. Incorporation of angular measurements using 3D imaging software increases diagnostic accuracy for the least amount of asymmetry present" [30].

The Wits appraisal is a simple linear measurement used as an adjunctive diagnostic tool which overcome the draw back of other analyses when invetisgating the anteroposterior skeletal relationship. Furthermore, it is very logical to consider that we should not treat patient according to numbers. It is noteworthy to remember that cephalometric interpretation not only depends on a number of different values and also not to only one single absolute value [24].This was confirmed by Jacobson, who stated that no single parameter in cephalometric should be depend upon as the only absolute value [9]. Wits appraisal could be more reliable than the ANB angle when assessing the sagittal dental base discrepancy. This is in line to findings from other previous published studies [9], [31], [32]. Accordingly it is recommended to use the Wits appraisal as a moderator of the ANB angle in treatment of orthodontic patients in boader line cases [22].

\section{CONCLUSION}

The Wits appraisal among Qatari females was $-0.62 \pm 3.8$ which is in accordance to Jacobson data. Care should be taken in growing children where the effect of dental height variations may confused the Wits value.The Wits appraisal could be used as a moderator to ANB angle in boader line cases. Incorporating angular measurements using 3D imaging software which increases diagnostic accuracy for the least amount of descrepancy present is highly recommended.
We would like to thank Hamad Medical Corporation/ Hamad Medical Research Center for sponsoring this research (Sub-Research Proposal Number 15041/150). The authors heartily acknowledge Dr. Hashim AL-Hussain for his help in statistical analysis procedure of this study. Thanks, extended to Dr. Mutaz Ahmed for his invaluable comments and support and to professor Anil Sukumaran for preparing the final temple.

\section{REFERENCES}

[1] Broadbent BA new X-ray technique and its application to orthodontia. Angle Orthod.;51:93-114.1931.

[2] Hofrath H. Bedeutung der röntgenfern und abstands aufnahme fürdie diagnostik der kieferanomalien. Fortschritte der Orthodontie.;1:23158. 1931.

[3] Downs WB. Variations In Facial Relationship: Their Significance In Treatment and Prognosis1. Angle Orthod.; 19:145-55. 1949.

[4] Steiner CC. Cephalometrics for you and me. Am J Orthod.;39:729-55. 1953.

[5] Tweed $\mathrm{CH}$. The Frankfort-Mandibular Incisor Angle (FMIA) In Orthodontic Diagnosis, Treatment Planning and Prognosis.Angle Orthod.;24:121-69.1954.

[6] Mills JR. Principles and Practice of Orthodontics. Churchill Livingstone, Edinburgh.1982.

[7] Sassouni V. A roentgenographic cephalometric analysis of cephalofacio-dental relationships. Am J Orthod. 41:735-64.1955.

[8] Ricketts, R. M. Cephalometric Analysis And Synthesis. Angle Orthod.;67:141-56. 1961.

[9] Jacobson, A. The Wits appraisal of jaw disharmony. Am J Orthod.;67:125-38. 1975.

[10] McNamara, J. A., Jr. A method of cephalometric evaluation." Am J Orthod.;86:449-69.1984.

[11] Riedel RA.The relation of maxillary structures to cranium in malocclusion and in normal occlusion. Angle Orthod.;22:142-45. 1952.

[12] Steiner CC. Cephalometrics in clinical practice. Angle Orthod.;29:829. 1959.

[13] Ricketts RM. The influence of orthodontic treatment on facial growth and development. Angle Orthod.;30:103-33.1960.

[14] Chang HP. Assessment of anteroposterior jaw relationship. Am J Orthod Dentofacial Orthop.;92:117-22, 1987.

[15] Bishara SE, Fahl JA, Peterson LC. Longitudinal changes in the ANB angle and Wits appraisal: Clinical implications. Am J Orthod.;84:13339. 1983.

[16] Jacobson A. Application of the "Wits" appraisal. Am J Orthod.;70:179-89. 1976.

[17] Jarvinen S. Relation of the Wits appraisal to the ANB angle: A statistical appraisal. Am J Orthod Dentofacial Orthop.;94:432-35. 1988.

[18] Nanda RS. Growth changes in skeletal-facial profile and their significance in orthodontic diagnosis. Am J Orthod.;59:501-13. 1971.

[19] Jenkins DH. Analysis of orthodontic deformity employing lateral cephalometric radiography. Am J Orthod.;41:442-52. 1955.

[20] Robertson NR, Pearson CJ. The wits appraisal of a sample of the South Wales population. Br J Orthod.;7:183-84.1980.

[21] So LY, Davis J, King NM. Wits appraisal in Southern Chinese children. The Angle Orthodontist.;60:43-47. 1990.

[22] Ifesanya Joy Ucheonye, Adeyemi Abigail Tokunbo, Otuyemi Olayinka Donald. The Wits appraisal among a Nigerian sub-population: an assessment of dentalbase geometric factors. Braz J Oral Sc.;12:275-79. 2013.

[23] Al-Barakati SF. The wits appraisal in a Saudi population sample. Saudi Dent J.;14:89-92.2002.

[24] Khalid H. Zawawi. Comparison of Wits appraisal among different ethnic groups. J Orthod Sci.;1:88-91. 2012.

[25] Jagan Nath Sharma .Steiner's cephalometric norms for the Nepalese population. J Orthodont.;38:21-31. 2011.

[26] Al-Jame B, Artun J, Al-Azemi R, Behbehani F, Buhamra S. Lateral cephalometric norms for adolescent Kuwaitis: Hard tissue measurements. Med Princ Pract.;15:91-97. 2006.

[27] Connor AM, Moshiri F. Orthognathic surgery norms for American Black patients. Am J Orthod.;87:119-34.1985.

[28] Rongo, R., D'Antò, V., Bucci, R. Polito, I.. Martina, R. , \& Michelotti, A.). Skeletal and dental effects of Class III orthopaedic treatment: A systematic review and meta-analysis. J Oral Rehab.;44,545-62. 2017. 
[29] Woon, S. C., \& Thiruvenkatachari, BEarly orthodontic treatment for Class III malocclusion: A systematic review and meta-analysis. Am. J. of Orthod. and Dentofac. Orthoped.;151:28-52. 2017.

[30] Nadia Abou Kheir and Chung How Kau Measuring mandibular asymmetry in Class I normal subjects using 3D novel coordinate system. Ann Maxillofac Surg.;4:34-38. 2014.

[31] Zhou L, Mok C-W, Hägg U, McGrath C, Bendeus M, Wu J. Anteroposterior dental arch and jaw-base relationships in a population sample. Angle Orthod.;78:1023-29. 2008.

[32] Shendre S, Karan GK, Ravinarayana RPR, Mamtha T. Correlation of the anteroposterior relationships of the dental arch and jaw-base in subjects with class I, class II and class III malocclusions. Int J Contemporary Dent; 2:68-73. 2011. 